\title{
Kanser Sürecinde Üstbilişler, Psikolojik Sağlamlık ve Nüks Korkusu
}

\section{Metacognitions, Psychological Resilience and Fear of Recurrence in Cancer Process}

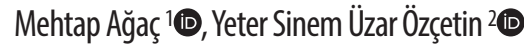

\section{$\ddot{0} z$}

Kanser, tüm dünyada sıklıkla görülen, bireyi hem fiziksel hem de psikolojik olarak etkileyebilen yaşamı tehdit edici bir hastalıktır. Kanser tanısı konulmasından yaşamın sonuna kadar olan ve sağkalım sürecini de içeren kanser yaşantısında, kanserin geri dönebileceğine veya ilerleyebileceğine dair endişeyi ifade eden nüks korkusu, bireylerin ve bakım verenlerinin en sık karşı karşıya kaldığı psikolojik sorunlardan biridir. Nüks korkusu klinik düzeye ulaşsığında, bireyler ve bakım verenler üzerinde yaşam kalitesinde azalma, işlevsellikte bozulma, rol performansında yetersizlik gibi olumsuz etkiler oluşturabilmektedir. Bu süreçte bireyin farkındalık düzeyini oldukça artıran üstbiliş kavramı, bireyin algılamaları ve yorumlamalarının yanı sıra hastalık sürecinden olumlu ya da olumsuz etkilenme olasilığını etkileyebilmektedir. Ayrıca ruh sağlığında koruyucu ve geliştirici bir faktör olan psikolojik sağlamlık kavramı da bu süreçte kişinin süreçten daha az zarar görmesini sağlayabilmekte ve iyi oluşluğunu artırabilmektedir. Bu sayede birey baş etme sistemlerini daha etkin kullanabilmekte ve süreci daha iyi yönetebilmektedir. Bu makalenin amacı, kanser sürecinde bireyin süreç̧en en az düzeyde zarar görmesini ve iyi oluşluğunu sağlamak üzere incelenmesi gereken üstbilişler, psikolojik sağlamlık ve nüks korkusu kavramlarının kanser süreci ile ilişkisinin açılkanması ve sürece etkilerinin değerlendirilmesidir.

Anahtar sözcükler: Kanser, nüks korkusu, üstbiliş, psikolojik sağlamlık, sağ kalanlar

\begin{abstract}
Cancer is a common life-threatening disease all over the world and can affect the people both physically and psychologically. Fear of recurrence is one of the most common psychological problems faced by individuals and their caregivers that is expressing the concern from diagnosis to the end of life that cancer may return or progress in cancer life even including the survivorship process. When the fear of recurrence reaches the clinical level, it can cause negative effects on individuals and their caregivers such as decreased quality of life, impaired functionality, and inadequate role performance. In this process, the concept of metacognition, which significantly increases the level of awareness of the individual, can have an effect on the individual's perceptions and interpretations as well as the possibility of being positively or negatively affected by the disease process. In addition, the concept of resilience, which is a protective and enhancing factor in mental health, can make less harm to the person from the process and increase their well-being. In this way, the individual can use coping strategies more effectively and manage the process better. In this paper, we aimed to explain the relationship between the concepts of metacognitions, resilience and fear of recurrence, and to evaluate their effects on the cancer process in order to ensure that the individual suffers minimal damage from the process and provide well-being.
\end{abstract}

Keywords: Cancer, fear of recurrence, metacognition, resilience, survivors

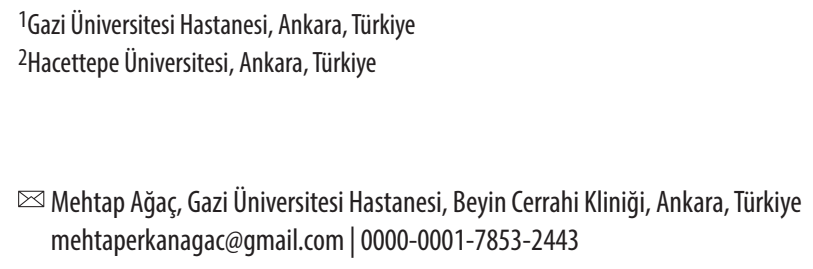

$凶$ Mehtap Ağaç, Gazi Üniversitesi Hastanesi, Beyin Cerrahi Kliniği, Ankara, Türkiye mehtaperkanaga@@gmail.com |0000-0001-7853-2443

Geliş tarihi/Received: 14.01.2021 | Kabul tarihi/Accepted: 04.03.2021 | Çevrimiçi yayın/Published online: 24.06 .2021 
DÜNYA genelinde ölüm nedenleri arasında ilk sıralarda yer alan kanser, her y1 milyonlarca bireyi etkilemekte ve oranlar her geçen y1l artmaya devam etmektedir (Ferlay ve ark. 2019). Tüm dünyada gelişen tıbbi ve teknolojik imkanlarla birlikte yeni kanser olgularındaki artışa paralel şekilde (Ferlay ve ark. 2019), kanser sonrası sağkalım oranları da her geçen gün artmaktadır (Howlader ve ark. 2015, Smith ve ark. 2017, Noone ve ark. 2018). Aktif tedavi sürecinin bitmesinin ardından, bireyin hastalık öncesi yaşantısına ve iyilik haline mümkün olduğunca dönebilmesi önemlidir. Dolayısıyla, kanser tanısı sonrası yaşam dengesini kurmaya çalışan, hayatta kalan bireyler, remisyon dönemi kanser hastalarıdır (Shi ve ark. 2011). Kanser sonrası sağkalım olarak adlandırdığımız bu süreçte, bireylerin kanser tedavisi sonrası sağlığına, günlük yaşamına ve yaşamın sonuna kadar olan sürece odaklandığı bilinmektedir. Öte yandan, sağkalım sürecinde kanserin fiziksel, psikososyal ve ekonomik sorunları devam etmektedir. Bu sorunlar; uyku problemleri, yorgunluk, halsizlik, bulant1-kusma, cinsel yaşamda sorunlar, vücutta değişimler gibi fiziksel; kaygı1, depresyon, ümitsizlik, kızgınlık, dikkat sorunları, rollerde değişim, yabancılaşma, nüks korkusu gibi psikolojik güçlükler olabilmektedir (Kim ve ark. 2012, Simard ve ark. 2013). Bu güçlükler, bireylerin baş etme becerilerini, gelecek planlarını, hastalık öncesi yaşamlarına tekrar uyum sağlayabilmelerini olumsuz etkileyebilmektedir (Simard ve ark. 2010). Yapılan çalışmalar (van den Beuken-van Everdingen ve ark. 2008, Allen ve ark. 2009, Simard ve ark. 2010), özellikle kanserin vücudun aynı yerinde veya başka bir bölümünde geri dönebileceği veya ilerleyebileceği endişesi olarak tanımlanan nüks korkusunun, remisyon döneminde bireylerin bakış açılarını ve uyumlarını ciddi ölçüde olumsuz etkilediğini, dolayısıyla yaşam kalitelerini bozduğunu göstermektedir. Bu çalışmalar incelendiğinde, Allen ve ark. (2009) bireylerin remisyon döneminde duygusal ve fiziksel zorlanmalarla karşılaştı̆̆ını, van den Beuken-van Everdingen ve ark. (2008) bu bireylerin en büyük kaygılarının hastalığın nüksüne yönelik olduğunu, Simard ve ark. (2010) ise nüks korkusunun tekrarlayıc1 nitelikteki, engellenemeyen girici bilişlerle ilişkili olduğunu göstermiştir. Tüm bu süreçlere ve deneyimlenen sorunlara yakından şahit olan bakım verenler, bu sürecin bir parçası olarak kabul edilmektedir (NCI 2020). Literatür incelendiğinde, nüks korkusunu, yalnızca kanser sürecini deneyimleyen bireyler değil, aynı zamanda bakım veren yakınları tarafından da yüksek oranlarda deneyimlendiği görülmektedir (Mellon ve ark. 2006, Mellon ve ark. 2007, Kim ve ark. 2012). Duygusal, fiziksel ya da maddi destek vermekten fazlasını içerdiği ve bakım verenin ruh sağlığı üzerine de etkilerinin olduğu bilinen bakım verme sürecinde (Northouse ve ark. 2012), hem hastalığı deneyimleyen birey hem de primer bakım vericinin kayg1 düzeyinde artış gözlenmektedir (Tan ve ark. 2020, Üzar-Özçetin ve Dursun 2020). Kayg1 düzeyindeki bu artı̧̧a işlevsellikte bozulma, yaşam kalitesinde azalma ve rollerin yerine getirilmesinde yetersizlik gibi sorunlar eşlik edebilmektedir (Mellon ve ark. 2007, Tan ve ark. 2020).

Nüks korkusunun birey ve bakım verenlerine sözü edilen etkilerinde ve bu etkilerin bireylerce algılanışında, çeşitli faktörler rol alabilmektedir. Bu faktörlerden birini dinamik bir süreci içeren üstbiliş kavramıdır. Üstbiliş, bireyin kendisi ile diğerlerinin farkına varması ve duygusal problemlerini çözebilme kapasitesi olarak tanımlanmaktadır 
(Jansen ve ark. 2015). Üstbilişlerin etkisiyle artan farkındalık, bireyin daha derin bir zihinsel süreç ile yönlendirilmesinde, duruma uyumunda ve işlevselliğini korumasında önemli bir işleve sahiptir (Wells 2000). Üstbilişsel sistemde herhangi bir sorun ortaya çıktığında, bireylerin psikolojik açıdan olumsuz etkilenme olasılı̆̆ı da artabilmektedir (Wells ve Cartwright-Hatton 2004, Allott ve ark. 2005). Bireysel algilamalar ve yorumlamaların süreci etkileyebilme olasılı̆̆ının yüksek olduğu kanser gibi kronik hastalıklarda ise, üstbilişlerin değerlendirilmesi, kanser yaşantısının anlamlandırılması ve bu yaşantı ile baş edilebilmesi aşamalarında etkili olabilmektedir. Bu anlamda, kanser sürecini yaşayan bireylerle yapılan çalışmalarda, düşünceler ve endişeler hakkındaki olumsuz inançlar ("düşüncelerimi her zaman kontrol etmeliyim", "endişselerim benim için tehlikelidir") gibi maladaptif üstbilişlerin nüks korkusunu artırdığ sonucuna ulaşılmıştır (Thewes ve ark. 2013, Butow ve ark. 2015). Öte yandan, Jansen ve ark. (2015) yaptığ çalı̧̧mada, bakım verenlerin adaptif üstbilişsel aktivitelerindeki artışın olumlu bakım verme deneyimlerini artırdığı sonucuna ulaşmıştır. Dolayısıyla üstbilişlerin hastaları olduğu kadar bakım verenleri de etkileme potansiyeli olduğu gösterilmiştir. Nüks korkusu üzerine çeşitli açılardan etkili olabilecek bir diğer faktör ise, psikolojik sağlamlıktır. Psikolojik sağlamlık, risk faktörleriyle karşılaşıldığında başarılı şekilde ruh sağlığını koruyabilme ve geri kazanabilme potansiyeli olarak tanımlanmaktadır (Hjemdal ve ark. 2007, Davydov ve ark. 2010) ve bireyin esneklik/uyum kapasitesini artırarak kanser yaşantısı sırasında kişisel iyi oluşu artırabilmektedir (Hudson ve ark. 2012, ÜzarÖzçetin ve Hiçdurmaz 2019). Böylece birey psikolojik sağlamlığın etkisiyle, kendisini yaşam problemlerinin üstesinden gelebilecek güçte hissetmekte, kanser süreci ile daha kolay baş edebilmektedir (Friborg ve ark. 2003, Üzar-Özçetin ve Hiçdurmaz 2017). Benzer şekilde, birey psikolojik sağlamlığın varlığı ile sürecin anksiyete (Hjemdal ve ark. 2014), depresyon (Hjemdal ve ark. 2007), benlik saygisında azalma (Haase ve ark. 2014) tükenmişlik (Üzar-Özçetin ve Dursun 2020) gibi olumsuz getirilerinden biri olabilen nüks korkusu ile daha etkin baş edebilme becerisini kazanabilmektedir (Walton 2017). $\mathrm{Bu}$ anlamda yapılan çalı̧̧malar, hem remisyon dönemindeki bireylerin (Üzar-Özçetin ve Hiçdurmaz 2019, Zuardin ve ark. 2019) hem de bakım verenlerinin ( $\mathrm{Li}$ ve ark. 2019, Üzar-Özçetin ve Dursun 2020) psikolojik sağlamlığ1 yüksek olduğunda süreçle daha iyi baş edebildiklerini göstermektedir.

Literatür değerlendirildiğinde, kanser sürecinde bireylerin deneyimledikleri problemler ile ilgili birçok çalışma bulunmaktadır. Ancak kanserle karşı karşıya kaldıklarında bireyleri savaşmaya, hayatta kalmaya ve hatta büyümeye iten kavramlar hakkında çok az şey bilinmektedir. Vurgulandığı üzere üstbilişler ve psikolojik sağlamlık, kanser sürecinde hem sağ kalan bireylerin hem de bakım verenlerin yaşamakta oldukları zorlukların üstesinden gelebilmesinde önemli etkilere sahiptir. Bu üç kavramın, kanser yaşantısıyla ilişkilerinin ve sürece olası etkilerinin değerlendirilmesi, kanser deneyimini yaşayan bireylerle çalışan sağlık ekibi üyelerinin hem deneyimlenen süreci daha iyi anlamalarına hem de bireylerin ve bakım verenlerinin güçlenmelerine katkı sağlayabilecek müdahalelerin planlanmasında önemli olabilir. 
$\mathrm{Bu}$ makalede, ülkemiz literatüründe kanser yaşantısı bağlamında hakkında sınırlı yayın olduğu göze çarpan nüks korkusu, üstbilişler ve psikolojik sağlamlık kavramlarının açıklanması ve süreç üzerine olası etkilerinin ortaya konması amaçlanmıştır.

\section{Kanser yaşantısı ve nüks korkusu}

Kanser sonrası sağkalım, yaşamın daha anlamlı hale gelmesi ve değer kazanması gibi olumlu etkiler oluşturabilmekle birlikte, tıbbi tedavilerin yan etkileri, fiziksel kısıtlamalar ve nüks korkusu gibi olumsuz yaşantıları da içermektedir (Doyle 2008). Bu istenmeyen yaşantılar içerisinde, bireyler ve bakım verenlerini en çok etkileyen faktörlerden biri nüks korkusudur (Savard ve Ivers 2013, Lambert ve ark. 2013, Simard ve ark. 2013). "Kanserin geri gelme veya ilerleme olasılığıyla ilgili korku, endişe” olarak tanımlanan nüks korkusunun, ortaya çıkmasındaki en büyük etmenlerden biri, kanserin yaşamı tehdit edici bir hastalık olarak algılanmasıdır (Mullens ve ark. 2004, Simard ve ark. 2010). Nüks korkusu çoğunlukla hastalıkla ilgili ortak algı ya da inançlardan ve hastalığın temsilinden köken almakta, kanserin mortalitesine ve evresine göre değişik düzeylerde ortaya çıkmaktadır (Simard ve ark. 2013). Sık görülen ve/veya mortalite oranları yüksek olan kanser türlerine ilişkin tanı alan bireyler, nüks korkusunu daha yoğun yaşamaktadır (Golden-Kreutz ve ark. 2005, Ries ve ark. 2006). Ancak, bu korkunun hemen hemen tüm kanser hastalarında oldukça yaygın olduğu, remisyon dönemi de dahil çeşitli düzeylerde devam ettiği ve yaşam kalitesini düşürücü etkiler gösterdiği bilinmektedir (Simard ve ark. 2010, Savard ve Ivers 2013, Lambert ve ark. 2013, Simard ve ark. 2013, Janz ve ark. 2016). Nüks korkusunun şiddeti değişebilmekle beraber tedavi bitiminden uzun süre sonra bile devam etmekte (Champagne ve ark. 2018) ve zamanla stabil kaldığı düşünülmektedir (Matthews 2003). Dolayısıyla, nüks korkusu yeni semptomların ortaya çıkması, tedavinin devam eden yan etkileri (Crist ve Grunfeld 2013), ylllk kontrollerle (Simonelli ve ark. 2017) ve tedavinin tamamlanmasiyla (Krok-Schoen ve ark. 2018) tetiklenebilmektedir.

Kanserden sonra sağ kalan bireylerde potansiyel nüks belirtileri konusunda uyanık kalmak ve tıbbi rejimlere uymak gibi kendi kendine koruyucu tepkiler ortaya çıkmasına neden olduğundan bir düzeye kadar nüks korkusu normal ve fonksiyonel olarak kabul edilebilmektedir (Lebel ve ark. 2016). Ancak nüks korkusu, bireylerin duygu durumlarını (Crist ve Grunfeld 2013), yaşam kalitesini (Koch ve ark. 2013) ve günlük işleyişlerini (Tan ve ark. 2020) zararlı şekilde etkileyen kronik bir endişe haline de gelebilmektedir. Dolayısıyla, nüks korkusu düşük düzeylerde sadece geçici anksiyete belirtileri ile seyrederken orta ve yüksek düzeyde olduğunda psikolojik sıkıntının daha yoğun olduğu, işlevsellikte ve yaşam kalitesinde daha fazla azalma olduğu görülmektedir (Simard ve ark. 2013, Thewes ve ark. 2013, Simard ve Savard 2015). Klinik nüks korkusu olarak da adlandırılan yoğun nüks korkusu, zamanla kendiliğinden düzelmez ve kanser tedavisinin tamamlanmasından sonra da uzun süre devam edebilir (Savard ve Ivers 2013, Simard ve ark. 2013). Yüksek düzeyde nüks korkusu yaşayan bu bireylerde, kanserin nüksetmesine dair düşünceler sürekli bir hal almakta, kişinin baş etme mekanizmalarına bağlı olarak kişide hazırlayıcı faktörlere (kanser belirtileri, çevreden gelen uyaranlar gibi) göre farklı tepkiler oluşabilmektedir. Tüm bu bilişsel 
faaliyetler, psikolojik problemler ile yakından ilişkili olduğu belirlenen nüks korkusunun, yoğun şekilde yaşandığı durumlarda yaşam kalitesini bozduğu (Koch ve ark. 2014), algılanan semptom yüklerini artırdığg1 (Simard ve ark. 2010), psikolojik uyuma, gelecek hakkındaki düşüncelere ve genel iyi oluş düzeyine olumsuz etkilerinin olduğu (Thewes ve ark. 2012), kişilerarası süreçlerde zorluklara yol açtığı (Simard ve ark. 2013) ve mental sağlı̆̆a zarar verdiği (Lebel ve ark. 2016) bildirilmektedir. Bununla birlikte klinik düzeyde nüks korkusu, fiziksel semptomların yanlış yorumlanması, semptomların nüksü temsil ettiği inancı (Liu ve ark. 2011), sürekli gergin ve tetikte durma davranışı, sağlık personellerinden ve diğer kaynaklardan sürekli güvence arama (Lebel ve ark. 2013) ya da bunların hepsinden kaçınma şeklinde sağlık bakım davranışlarını değiştirebilmektedir (Crist ve Grunfeld 2013, Simard ve ark. 2013).

Sözü edilen psikososyal problemler, yalnızca hastaları değil bakım verenlerini de etkilemektedir (Kim ve ark. 2012, Simard ve ark. 2013). Öyle ki bakım verenlerde nüks korkusu yaygınlık oranlarının hastalara oranla daha yüksek bulunduğu çalışmalara rastlanmaktadır (Maguire ve ark. 2017, van de Wal ve ark. 2017). Dolayısıyla, nüks korkusu ile ilgili endişeleri yönetmek, bakım verenler için de yaygın olarak bildirilen karşılanmamış bir ihtiyaçtır (Maguire ve ark. 2017). Bu durum, bakım verenlerde artan duygusal strese (van de Wal ve ark. 2017), yalnızlığa (Boehmer ve ark. 2016) ve daha düşük yaşam kalitesine (Stein ve ark. 2008, Janz ve ark. 2016) yol açmaktadır. Han ve ark. (2016) yaptıkları çalışma sonucunda kanser sürecinde bakım verenlerin hastalığın belirsizliğine bağlı suçluluk ve yoğun kaygı yaşadıklarını belirlemiştir. van de Wal ve ark. (2017) ise, kanser sürecinde bakım veren eşlerde yüksek düzeylerde nüks korkusu olduğunu göstermiştir. Benzer şekilde Maguire ve ark. (2017) çalışmalarında banım verenlerin nüks korkusu yaşadıklarını ve bu korkunun yaşadıkları stresi artırdığını bulmuştur. Öte yandan, bakım verenin nüks korkusu ile ilişkili değişkenler arasında daha genç yaş (Janz ve ark. 2016, Maguire ve ark. 2017, van de Wal ve ark. 2017), kanser şiddeti (Kim ve ark. 2012), tedavi tipi (Boehmer ve ark. 2016, Janz ve ark. 2016, Maguire ve ark. 2017, Wu ve ark. 2019) ve tanıdan beri geçen süre (Boehmer ve ark. 2016, Lin ve ark. 2016, Maguire ve ark. 2017) yer almaktadır. Bu değişkenler incelendiğinde, genç yaşta bakım veremeye başlayan (Janz ve ark. 2016, Maguire ve ark. 2017, van de Wal ve ark. 2017) ve bakım verdiği yakında ileri evre kanser olan (Kim ve ark. 2012) bireylerde daha yoğun bir nüks korkusu yaşandığg görülmektedir. Benzer şekilde, bakım verenin nüks korkusu düzeyini, ailede stres düzeyinin yüksek olması (Mellon ve ark. 2007), kansere olumsuz anlamlar yükleme (ölüm, acı çekme, ağrı, vb.), sağ kalan bireyin yaşam kalitesinde ve iyilik halindeki düşme (Kim ve ark. 2012), bakım aktiviteleri için harcanan daha fazla zaman (Maguire ve ark. 2017) gibi faktörler etkilemektedir. Bu bağlamda, Kim ve ark. (2012) tarafından yapılan çalışma sonucunda, kanser sürecinden olumsuz etkilenimlerin hem hastaların hem de bakım verenlerin nüks korkusuyla ilişkili olduğu bulunmuştur. Başka bir çalı̧mada ise, yüksek düzeyde nüks korkusunun bakım verenin zihinsel ve fiziksel sağlı̆̆ını düşürdüğü belirtilmiştir (Lin ve ark. 2016). Bakım verenlerde nüks korkusu, yaşam kalitesi ile negatif, psikolojik sıkıntı ile pozitif ilişkili bulunmuştur (Simard ve ark. 2013). Bununla birlikte bakım verenler çoğunlukla remisyon dönemindeki bireyi 
olumsuz etkileyebileceğinden endişe ettikleri için, nüks korkusuna ilişkin kendi korkularını ifade etmekten sıklıkla korkmaktadırlar ve böylece korku düzeyleri daha da artmaktadır (Soriano ve ark. 2018). Ancak, bakım verme sürecine kendini hazırlamış bakım verenlerin, yakınlarının iyilik halini artırdı̆̆ı bilinmektedir (Northouse ve ark. 2012). Tüm bunlardan yola çıkarak; literatür remisyon dönemi kanser hastaları ve bakım verenler arasında nüks korkusunun ortak bir deneyim olduğunu, kanser süreci boyunca kalıcı olabildiğini ve yaygın olarak görülebildiğini göstermektedir.

\section{Üstbilişler ve kanser yaşantısı}

Üstbiliş kavramı, bireyin kendi zihnindeki işlev ve olayların farkında olup, bunları kontrol etmesini ve amaçlı olarak yönlendirebilmesini içeren üst düzey bilişsel sistemdir (Flavell 1979, Wells 2000, Tosun ve Irak 2008). Bununla birlikte üstbiliş, kendine özgü düşünceyi fark etmeyi, duygusal tepkilerini anlamlandırabilme becerisini, kişinin düşüncelerini öznel olarak görme ve başkalarının bakı̧̧ açısının kendisininkinden farklı olabileceğini anlama yeteneği olarak da tanımlanmaktadır (Lysaker ve ark. 2005, Carcione ve ark. 2011, Lysaker ve ark. 2011). Wells (2009) tarafından geliştirilen “Üstbiliş Kuramı”, düşünce ve duygulardaki bozulmaların temelinde üstbilişlerin olduğunu belirtmektedir. Üstbiliş kuramı, bireyin hangi otomatik düşünce ve inançlara sahip olduğundan ziyade, bunlara verdiği tepkilere odaklanmaktadır (Wells ve Matthews 1996). Verilen tepkilerin belirleyicisi ise, bireyin üstbilişleridir. Üstbiliş sistemi, insanın işlevsel ve işlevsel olmayan bilişsel süreçlerinin kontrolünden sorumludur ve uyuma yönelik çalışmasında önemli bir rolü vardır (Wells ve Matthews 1996, Wells ve Cartwright-Hatton 2004). Bu bağlamda, uyumsuz üstbilişlerin psikolojik bozuklukların gelişimi ve sürdürülmesinde işlevsiz düşünce ve başa çıkma stillerinin ortaya çıkmasında etkili olduğu söylenebilir (Cartwright-Hatton ve Wells 1997).

Bilişsel süreçlerin işlevinde ve uyumunda önemli bir yeri olan üstbilişlerde ortaya çıkan herhangi bir sorunun, bireylerin psikolojik açıdan olumsuz etkilenme olasılığını artıracağ (Wells ve Cartwright-Hatton 2004, Allott ve ark. 2005), birçok psikopatolojinin gelişmesi ve sürmesinde önemli bir hazırlayıcı faktör olacağı düşünülmektedir (Wells ve CartwrightHatton 2004). Birey olayları değerlendirirken bazı olumlu ya da olumsuz üstbilişlere sahip olmakta, bu üstbilişler kişinin olaya verdiği tepkiyi ve uyumu şekillendirmektedir (Wells ve Cartwright-Hatton 2004). Bir çalışmada üstbilişler, hem algılanan stres hem de psikososyal sorunlar (anksiyete, depresyon, vb.) ile olumlu ve anlamlı düzeyde ilişkili bulunmuştur (Spada ve ark. 2008). Dolayısıyla, tüm yaşamsal süreçlerde olduğu gibi hastalık sürecinde de üstbilişler aktive olmakta, özellikle kanser gibi bireyin yaşantısını etkileme potansiyeli yüksek hastalıklarda, bireyin hastalık algısını, tedavi süreçlerini ve uyumunu etkileyebilmektedir (Thewes ve ark. 2012, Butow ve ark. 2015). Dolayssiyla, bireysel algilamalar ve yorumlamaların süreci etkilemesi bakımından kanser gibi kronik hastalıklarda bilişsel süreçlere eğilmek oldukça önemlidir (Lee-Jones ve ark. 1997, Mullens ve ark. 2004, McGinty ve ark. 2012). Bu anlamda, yapılan araştırma sonuçlarında üstbilişlerin bireylerin kanser sürecini yönetimini etkilediği görülmekte ve aynı zamanda uyumsuz üstbilişlerin, nüks korkusu ile pozitif ilişkisi olduğu bulunmuştur (Thewes ve ark. 2012, Thewes ve ark. 
2013, Butow ve ark. 2015). Yine Lee-Jones ve ark. (1997) yaptıkları çalışmada, kanser hakkındaki inançların, kanserle ilgili önceki deneyimlerin ve kanser hakkındaki bilginin; bilişsel boyutları güçlü bir şekilde etkileyebildiği belirtilmektedir. Psikolojik faktörleri anlamanın bir yolu, altta yatan üstbilişlerin değerlendirilmesidir (Semerari ve ark. 2003, Dimaggio ve ark. 2007). Üstbilişler, bakım verme deneyimini de etkileyebilmektedir. Çünkü bakım verme sürecinde, hasta bireyin yaşadığ 1 durumu ve endişesini anlayabilmek ve duruma uyum sağlayabilmek için sezgisel olarak daha fazla üstbilişsel kapasite gerektiği düşünülmektedir (Butow ve ark. 2015). Bakım verenlerin daha düşük, diğer bir deyişle maladaptif üstbilişsel kapasiteye sahip olmasının, süreci daha karmaşık hale getirerek, bakım veren ve hasta arasında paylaşımların azalmasına ve daha az olumlu deneyim yaşanmasına yol açtığı bilinmektedir. Ayrıca, daha adaptif üstbilişsel kapasite ile aile üyelerinin kendi sıkıntılarını daha iyi yönetebildikleri ve olayları hem iyi hem de acı veren öğelerin bulunmasına izin verecek bir bakış açısıyla görmelerinin olası olduğu görülmüştür (Lysaker ve ark. 2011). Bu anlamda yapılan bir çalışmada, adaptif üstbilişsel kapasite, bakım verme ile ilgili daha olumlu deneyimlerle ilişkilendirilirken, tersi durumda ise bakım verme ile ilgili daha olumsuz deneyimlerle karşılaşıldığı bulunmuştur (Jansen ve ark. 2015). Dolayısıyla bilişsel süreçlerin, kanser hastaları ve bakım verenlerin sürece yüklediği anlamı, psikolojik uyumunu, sürecin etkin yönetimini etkileyebileceği görülmektedir.

$\mathrm{Bu}$ etkiler, remisyon döneminde dahi devam edebilmekte, daha önce sözü edilen nüks korkusu gibi ruhsal sağlığı etkileyen durumlarda ise maladaptif bilişlere yol açarak hastalığa verilen tepkileri olumsuz etkilemektedir (Lysaker ve ark. 2011, Jansen ve ark. 2015). Bu maladaptif bilişler, kişilerin hastalığa verdiği tepkiyi belirlemektedir. Dolayısıyla, söz konusu maladaptif bilişler, uyum bozucu ve fonksiyonel olmayan düşünce ve davranışların oluşmasına yol açmakta ve böylece nüks korkusunun ortaya çıkışını desteklemektedir (Thewes ve ark. 2013). Nüks korkusunun üstbilişler ile ele alınması; bilişsel süreçlere odaklanmanın öneminin kavranması, daha kabul edilebilir inançların ortaya çıkarılması ve kanser sonrası artan duygusal tepkilerin devam etme nedenlerinin açıklanmasına katkı sağlamaktadır (Llewellyn ve ark. 2008, Baker ve ark. 2005, Butow ve ark. 2015, Erkan 2019). Ayrıca nüks korkusunun maladaptif bilişler çerçevesinde ele alınması ve buna yönelik etkin girişimlerin planlanması ve uygulanması kontrol edilemeyen nüks korkusunun yönetilmesine yardımcı olmaktadır (Fardell ve ark. 2016).

\section{Psikolojik sağlamlık ve kanser yaşantısı}

Yaşamları boyunca tüm bireyler çeşitli güçlüklerle karşı karşıya kalmaktadır (Masten 2014). $\mathrm{Bu}$ güçlüklerle baş etmede ve uyumun sağlanmasında psikolojik sağlamlık, önemli bir yere sahiptir (Wagnild ve Collins 2009, Basım ve Çetin 2011, Wu ve ark. 2013). Yaşamın ilk dönemlerinden itibaren çeşitli düzeylerde var olan ve bireyin sonraki yaşantısında geliştirilebilme potansiyeli taşıyan psikolojik sağlamlık kavramı, bireyin zorlu yaşam stresörleri ile karşı karşıya geldiğinde bu olumsuz etmenlerin üstesinden gelerek tekrar eski durumuna dönebilmesi olarak tanımlanmaktadır (Wagnild ve Collins 2009, Wu ve ark. 2013). Bu kavram, bireyin içsel ve dışsal destek kaynaklarına ve sosyal becerilerine göre 
şekillenmekte (Hjemdal ve ark. 2007) ve stres oluşturan risk faktörlerine karşı koruyucu faktörlerin varlığı ile geliştirilebilme potansiyeli taşımaktadır (Öz ve Y1lmaz 2009, Basım ve Çetin 2011).

Son derece stresli bir deneyim olan kanser süreci ile birey, duygusal sıkıntı, depresyon, anksiyete, uyku sorunları, yorgunluk ve bozulmuş yaşam kalitesi gibi uzun süreli olumsuz psikolojik sonuçlara karşı savunmasız hale gelebilir (Seiler ve Jenewein 2019). Yaşanan güçlüklerle etkin baş edememe, sorunların çözümünde yetersizlik, kronik stres düzeyine sahip olma gibi olumsuz deneyimler, psikolojik sağlamlık düzeyinin düşük olması ile ilişkili olarak değerlendirilmektedir (Davydov ve ark. 2010). Öte yandan, sorunlarla işlevsellikte düşüs olmaksızın; psikososyal açıdan minimal düzeyde etkilenme ya da hiç etkilenme yaşamadan, uygun baş edebilme durumu, psikolojik sağlamlık düzeyinin yüksek olması ile açıklanmaktadır (Luthar ve ark. 2000, Bonanno ve ark. 2004). Bireyin iyimser, umut dolu, motive olmuş (Min ve ark. 2013) ve sosyal destek sistemine sahip olması (RistevskaDimitrovska ve ark. 2015) gibi öncül faktörler psikolojik sağlamlığ1 güçlendirebilmektedir. Bu bağlamda, bazıları psikolojik sağlamlık bakımından diğerlerinden daha sağlam olmakla birlikte, her birey olumsuzluklara aynı şekilde tepki veremeye bilmektedir (Seiler ve Jenewein 2019).

Kanser teşhisi ve tedavisi ile ilişkili önemli sıkıntılara rağmen, bazı bireyler psikolojik sağlamlığın varlığı ile yaşanan sorunlarla baş edebilmekte ve süreci daha yapıcı bir şekilde değerlendirebilmektedir (Danhauer ve ark. 2013). Böylece, psikolojik sağlamlık kanser sürecinin üstesinden gelmenin, baş etmenin geliştirilmesi için zihinsel ve duygusal iyilik için bir fırsat olarak değerlendirilebilmektedir (Danhauer ve ark. 2013, Üzar-Özçetin ve Hiçdurmaz 2019). Dolayısıyla, bu süreçte yaşanan zorluklar ile mücadelede, psikolojik sağlamlığın varlığı önemli olmaktadır (Haase ve ark. 2014, Hjemdal ve ark. 2014). Kanser yaşantısında bireyin ruh sağlı̆̆ını dış etkenlerden koruyan psikolojik sağlamlık (Davydov ve ark. 2010), bireyin yaşamında anlam bulmasını sağlamakta, olumlu beklentileri ve iyilik halini artırmaktadır (Ickovics ve ark. 2006). Literatür incelendiğinde, yapılan çalışmalar psikolojik sağlamlığ1 yüksek olan kişilerin baş etme yöntemlerinin daha etkili olduğunu belirtmektedir (Connor ve ark. 2003, Haase ve ark. 2014). Bunlara ek olarak yüksek psikolojik sağlamlığa sahip bireylerin düşük psikolojik problem (Min ve ark. 2013), daha az anksiyete (Cuhadar ve ark. 2016) ve depresyon (Hu ve ark. 2018) yaşadığı ve yaşam kalitelerinin (Tian ve Hong 2014, Matzka ve ark. 2016) daha yüksek olduğu görülmektedir. Aksine, daha düşük psikolojik sağlamlık düzeyi, psikolojik fonksiyonlarda bozulma ve kanser hastaları arasında tükenmişliğin artması ile ilişkili bulunmuştur (Strauss ve ark. 2007, Tian ve Hong 2014).

Daha önce de vurgulandı̆̆ı üzere, kanser süreci hasta birey kadar bakım verenin de dahil olduğu karmaşık ve uzun bir süreçtir ve hastayı olduğu kadar bakım veren yakınını da psikososyal olarak etkilemektedir (Erkan 2019, Üzar-Özçetin ve Dursun 2020). Bakım veren bireyde psikolojik sağlamlığın varlığı ile bakım veren-çevre etkileşimi ve koruyucurisk faktörleri arası dengenin korunabilme olasılı̆gı desteklenmektedir (Northouse ve ark. 2012, Lin ve ark. 2013). Bu dengenin sürecin daha iyi yönetilmesini sağladığ1 ve hastanın sürecin üstesinden gelmesini kolaylaştırdığı bilinmektedir (Lin ve ark. 2013, Rosenberg 
ve ark. 2013, Rosenberg ve ark. 2014). Fiziksel, psikolojik, duygusal, sosyal ve finansal gibi çeşitli stresörleri içinde barındıran bakım verme sürecinde (Dumont ve ark. 2008); psikolojik sağlamlık risk faktörlerinin etkilerini azaltarak ve olumsuz reaksiyonları en aza indirerek sürece olumlu katkıda bulunmaktadır (Zauszniewski ve ark. 2010, Bekhet ve ark. 2012). Aynı zamanda, bakım verenin psikolojik sağlamlığının yüksek olması bakımın kalitesini (Gaugler ve ark. 2007) ve etkili iletişimi artırmakta (Northouse ve ark. 2012), duygusal stres ve sıkıntıyı azaltmaktadır (Lin ve ark. 2013). Yapılan bir çalışma sonucunda, psikolojik sağlamlığı yüksek olan bakım verenlerin problem çözme, yaratıcılık, mizah, iletişim ve sosyal becerilerinin daha güçlü olduğu belirtilmiştir (Lin ve ark. 2013). Bununla beraber psikolojik sağlamlık düşüklüğü ile ruminasyon, endişe, perseveratif düşünme, tehdit izleme gibi yardımcı olmayan başa çıkma yöntemleri aktive olmakta ve psikolojik sorunlar ortaya çıkabilmekte (Öcalan ve Üzar-Özçetin 2020), bakım yükü artarken yaşam kalitesi azalmaktadır (Üzar-Özçetin ve Dursun 2020). Bunun yanında psikolojik sağlamlığın, bireyin yaşamına verdiği anlamı etkilediği ve olumlu bakış açısı geliştirdiği (Üzar-Özçetin ve Hiçdurmaz 2020) ve kanser sürecindeki travmatik yaşantılarını daha az tehdit edici algı1lamasını sağladığı (Ristevska-Dimitrovska ve ark. 2015, Erkan 2019), güç yaşam olayları sonrasında büyüyerek deneyim kazanmasına olanak sağladığı (Üzar-Özçetin ve Hiçdurmaz 2019) bilinmektedir. Ek olarak, kanserde yaşanan olumsuz süreçler uygun yönetildiğinde en az travmatik etki ile sürecin atlatılabilir, böylece psikolojik sağlamlığın artıp, kişisel büyüme gerçekleşebilir (Schmidt ve ark. 2012). Dolayısıyla psikolojik sağlamlığın geliştirilmesine yönelik yaklaşımların belirlenmesi uygulamaya aktarılması oldukça önemlidir.

\section{Sonuç}

Zorlu bir yaşantı olan kanser sürecinde bireyin iyilik halinin artırılması, kanser sürecinin yönetimini sağlamayı kolaylaştıracak ve bireyin yaşam kalitesini artıracaktır. Bu derlemede değinilen bilgiler ışığında, nüks korkusunun sadece hastayı ve bakım verenini değil aynı zamanda tıbbi bakımı da olumsuz yönde etkilediği görülmektedir. Kanser sonrası sağ kalan bireyin ve bakım verenin karşılanmamış gereksinimlerinin başında gelen nüks korkusunun, bireyde erken dönemde fark edilmesi, nüks korkusunun gelişimini ve şiddetini etkilenebilecek olan kavramlardan olan üstbilişler ve psikolojik sağlamlığın olumlu yönde geliştirilmesi ve bunu sağlayabilecek bireye yönelik müdahalelerin planlanması ve uygulanması; bireyin iyilik halini artıracaktır. Bu çalışmada kanser sürecinde arka planda kalan bakım verenlerin de yakınları ile benzer sorunları yaşadığı vurgulanırken, bu sürecin hem bireyleri hem de bakım verenlerine etkilerinin önemli düzeyde olduğu literatür verileriyle gösterilmiştir. Bireyin ve bakım verenin yaşamını derinden etkileyen bir yaşantı olan kanser sürecinde, bireyin duygu ve davranışlarının anlaşılmasının önemine dikkat çekilmiştir. Litetatür incelendiğinde bakım verenler de yoğun bir nüks korkusu bildirdiklerinden ve sağ kalanların nüks korkusunun bakım verenlerin nüks korkusunu etkilendiğinden söz edilmektedir. Bu durum, bakım verene yapılan müdahalelerin dolaylı olarak sağ kalanların, tam tersi sağ kalanların nüks korkusuna yönelik planlanan müdahalelerin de bakım verenlerin nüks korkusuna fayda sağlayacağ1 düşünülmektedir. Ayrıca hem hasta bireyler hem de bakım verenlerinde nüks korkunun 
azaltılması ve kontrol altına alınabilmesinde psikolojik sağlamlık ve adaptif üstbilişlerin işe yarayabileceği söylenebilir. Sözü edilen kavramların kanser deneyimini yaşayan bireylerin süreçlerine olası etkilerinin değerlendirilmesi ve bu doğrultuda etkin müdahale planlarının oluşturulması, bireylere ve bakım verenlerine verilebilecek desteğin niteliğinin artmasını sağlayabilir. Bu anlamda hem kanser sürecini deneyimleyen bireylerin hem de bakım verenlerinin süreçten daha güçlü şekilde çıkması ve mental sağlıklarının mümkün olan en üst düzeye çıkarılması için adaptif bilişlere odaklanan ve maladaptif bilişlerin daha adaptif olanları ile yer değiştirilmesi, ruminatif düşüncelerin kontrolü ve amaçlı hale gelmesi gibi yöntemleri içeren bilişsel terapi yaklaşımlarının benimsenmesi etkili olabilir. Benzer şekilde metakognitif terapi, farkındalık temelli yaklaşımlar, şema terapi ve destekleyici terapi gibi yaklaşımlar yoluyla bireylerin kaygı düzeyleri azaltılabilir. Bu bağlamda, ileride yapılması planlanan çalışmalarda sözü edilen yaklaşımların etkinliklerinin araştırılması önerilmektedir.

\section{Kaynaklar}

Allen JD, Savadatti S, Gurmankin Levy A (2009) The transition from breast cancer'patient'to 'survivor'. Psychooncology, 18:71-78.

Allott R, Wells A, Morrison AP, Walker R (2005) Distress in Parkinson's disease: contributions of disease factors and metacognitive style. Br J Psychiatry, 187:182-183.

Baker F, Denniston M, Smith T, West MM (2005) Adult cancer survivors: how are they faring? Cancer, 104: 2565-2576.

Basım HN, Çetin F (2011). Yetişkinler için psikolojik dayanıklılık ölç̧egi'nin güvenilirlik ve geçerlilik çalışması. Turk Psikiyatri Derg, 22:104-114.

Bekhet AK, Johnson NL, Zauszniewski JA (2012) Resilience in family members of persons with autism spectrum disorder: A review of the literature. Issues Ment Health Nurs, 33:650-656.

Bonanno GA, Wortman CB, Nesse RM (2004) Prospective patterns of resilience and maladjustment during widowhood. Psychol Aging, 19:260-271.

Boehmer U, Tripodis Y, Bazzi AR, Winter M, Clark MA (2016) Fear of cancer recurrence in survivor and caregiver dyads: differences by sexual orientation and how dyad members influence each other. J Cancer Surviv, 10:802-813.

Butow P, Kelly S, Thewes B, Hruby G, Sharpe L, Beith J (2015). Attentional bias and metacognitions in cancer survivors with high fear of cancer recurrence. Psychooncology, 24:416-423.

Carcione A, Nicolò G, Pedone R, Popolo R, Conti L, Fiore D et al. (2011) Metacognitive mastery dysfunctions in personality disorder psychotherapy. Psychiatry Res, 190:60-71.

Cartwright-Hatton S, Wells A (1997) Beliefs about worry and intrusions: The Meta-Cognitions Questionnaire and its correlates. J Anxiety Disord, 11:279-296.

Champagne A, Ivers H, Savard J (2018) Utilization of health care services in cancer patients with elevated fear of cancer recurrence. Psychooncology, 27:1958-1964.

Connor KM, Davidson JR, Lee LC (2003) Spirituality, resilience, and anger in survivors of violent trauma: A community survey. J Trauma Stress, 16:487-494.

Crist JV, Grunfeld EA (2013) Factors reported to influence fear of recurrence in cancer patients: a systematic review. Psychooncology, 22:978-986.

Cuhadar D, Tanriverdi D, Pehlivan M, Kurnaz G, Alkan S (2016) Determination of the psychiatric symptoms and psychological resilience levels of hematopoietic stem cell transplant patients and their relatives. Eur J Cancer Care, 25:112-121.

Danhauer SC, Russell GB, Tedeschi RG, Jesse MT, Vishnevsky T, Daley K et al. (2013) A longitudinal investigation of posttraumatic growth in adult patients undergoing treatment for acute leukemia. J Clin Psychol Med Settings, 20:13-24.

Davydov DM, Stewart R, Ritchie K, Chaudieu I (2010) Resilience and mental health. Clin Psychol Rev, 30:479-495.

Dimaggio G, Semerari A, Carcione A, Nicolō G, Procacci M (2007) Psychotherapy of Personality Disorders: Metacognition, States of Mind and Interpersonal Cycles. New York, Routledge.

Doyle N (2008) Cancer survivorship: evolutionary concept analysis. J Adv Nurs, 62:499-509. 
Dumont S, Fillion L, Gagnon P, Bernier N (2008) A new tool to assess family caregivers' burden during end-of-life care. J Palliat Care, 24:151-161.

Erkan M (2019) Kanser sonrası sağ kalan bireyler ve bakım verenlerinde psikolojik sağlamlık ve üstbilişlerin nüks korkusu ile ilişkisi (Yüksek lisans tezi). Ankara, Hacettepe Üniversitesi.

Fardell JE, Thewes B, Turner J, Gilchrist J, Sharpe L, Girgis A et al. (2016) Fear of cancer recurrence: a theoretical review and novel cognitive processing formulation. J Cancer Surviv, 10:663-673.

Ferlay J, Colombet M, Soerjomataram I, Mathers C, Parkin D, Piñeros M et al. (2019). Estimating the global cancer incidence and mortality in 2018: GLOBOCAN sources and methods. Int J Cancer, 144:1941-1953.

Flavell JH (1979). Metacognition and cognitive monitoring: A new area of cognitive-developmental inquiry. Am Psychol, 34:906-911.

Friborg 0, Hjemdal 0, Rosenvinge JH, Martinussen M (2003). A new rating scale for adult resilience: what are the central protective resources behind healthy adjustment? Int J Methods Psychiatr Res, 12:65-76.

Gaugler JE, Kane RL, Newcomer R (2007) Resilience and transitions from dementia caregiving. J Gerontol B Psychol Sci Soc Sci, 62:3844.

Golden-Kreutz DM, Thornton LM, Gregorio WD, Frierson GM, Jim HS, Carpenter KM et al. (2005) Traumatic stress, perceived global stress, and life events: prospectively predicting quality of life in breast cancer patients. Health Psychol, 24:288-296.

Haase JE, Kintner EK, Monahan PO, Robb SL (2014) The resilience in illness model (RIM) Part 1: Exploratory evaluation in adolescents and young adults with cancer. Cancer Nurs, 37:E1-E12.

Han JH, Han SH, Lee MS, Kwon HJ, Choe K (2016) Primary caregivers' support for female family members with breast or gynecologic cancer. Cancer Nurs, 39:E49-E55.

Hjemdal 0, Aune T, Reinfjell T, Stiles TC, Friborg 0 (2007) Resilience as a predictor of depressive symptoms: a correlational study with young adolescents. Clin Child Psychol Psychiatry, 12:91-104.

Hjemdal O, Hagen R, Ottesen Kennair Leif E, Solem S, Wells A, Nordahl H (2014) Resilience and metacognitions as predictors of outcome in a randomized controlled treatment trial of generalized anxiety disorder. In MEDIMOND. Proceedings of the Second World Congress on Resilience: From Person to Society (Ed S Ionescu):1083. May 8-10 2014, Timisoara, Romania.

Howlader N, Noone A, Krapcho M, Garshell J, Miller D, Altekruse S et al. (2015) SEER cancer statistics review, 1975-2012. National Cancer Institute, https://seer.cancer.gov/archive/csr/1975_2012/ (Accessed 12.10.2020).

Hu T, Xiao J, Peng J, Kuang X, He B (2018) Relationship between resilience, social support as well as anxiety/depression of lung cancer patients: A cross-sectional observation study. J Cancer Ther Res, 14:72.

Hudson SV, Miller SM, Hemler J, Ferrante JM, Lyle J, Oeffinger KC, DiPaola RS (2012) Adult cancer survivors discuss follow-up in primary care:'not what I want, but maybe what I need'. Ann Fam Med, 10(5):418-427.

Ickovics JR, Milan S, Boland R, Schoenbaum E, Schuman P, Vlahov, D et al. (2006). Psychological resources protect health: 5-year survival and immune function among HIV-infected women from four US cities. AIDS, 20:1851-1860.

Jansen JE, Harder S, Haahr UH, Lyse HG, Pedersen MB, Trauelsen AM et al. (2015) The Role of Metacognitions in Expressed Emotion and Distress: A Study on Caregivers of Persons with First-Episode Psychosis. Clin Psychol Psychother, 22:525-532.

Janz NK, Li Y, Beesley LJ, Wallner LP, Hamilton AS, Morrison RA et al. (2016) Worry about recurrence in a multi-ethnic population of breast cancer survivors and their partners. Support Care Cancer, 24(11):4669-4678.

Kim Y, Carver CS, Spillers RL, Love-Ghaffari M, Kaw CK (2012) Dyadic effects of fear of recurrence on the quality of life of cancer survivors and their caregivers. Qual Life Res, 21:517-525.

Koch L, Bertram H, Eberle A, Holleczek B, Schmid-Höpfner S, Waldmann A et al. (2014) Fear of recurrence in long-term breast cancer survivors - still an issue. Results on prevalence, determinants, and the association with quality of life and depression from the Cancer Survivorship —a multi-regional population-based study. Psychooncology, 23:547-554.

Koch L, Jansen L, Brenner H, Arndt V (2013) Fear of recurrence and disease progression in long-term ( $\geq 5$ years) cancer survivors—a systematic review of quantitative studies. Psychooncology, 22:1-11.

Krok-Schoen JL, Naughton MJ, Bernardo BM, Young GS, Paskett ED (2018) Fear of recurrence among older breast, ovarian, endometrial, and colorectal cancer survivors: Findings from the WHI LILAC study. Psychooncology, 27:1810-1815.

Lambert SD, Girgis A, Lecathelinais C, Stacey F (2013) Walking a mile in their shoes: Anxiety and depression among partners and caregivers of cancer survivors at 6 and 12 months post-diagnosis. Support Care Cancer, 21:75-85.

Lebel S, Simard S, Harris C, Feldstain A, Beattie S, McCallum M et al. (2016) Empirical validation of the English version of the Fear of Cancer Recurrence Inventory. Qual Life Res, 25:311-321. 
Lebel S, Tomei C, Feldstain A, Beattie S, McCallum M (2013) Does fear of cancer recurrence predict cancer survivors' health care use? Supportive Care Cancer, 21:901-906.

Lee-Jones C, Humphris G, Dixon R, Bebbington Hatcher M (1997) Fear of cancer recurrence-a literature review and proposed cognitive formulation to explain exacerbation of recurrence fears. Psychooncology, 6:95-105.

LiY, Qiao Y, Luan X, LiS, Wang K (2019) Family resilience and psychological well-being among Chinese breast cancer survivors and their caregivers. Eur J Cancer Care, 28:e12984.

Lin CR, Chen SC, Chang JTC, Fang YY, Lai YH (2016) Fear of cancer recurrence and its impacts on quality of life in family caregivers of patients with head and neck cancers. J Nurs Res, 24:240-248.

Lin FY, Rong JR, Lee TY (2013) Resilience among caregivers of children with chronic conditions: a concept analysis. J Multidiscip Healthc, 6:323.

Liu Y, Pérez M, Schootman M, Aft RL, Gillanders WE, Jeffe DB (2011) Correlates of fear of cancer recurrence in women with ductal carcinoma in situ and early invasive breast cancer. Breast Cancer Res Treat, 130:165.

Llewellyn CD, Weinman J, McGurk M, Humphris G (2008) Can we predict which head and neck cancer survivors develop fears of recurrence? J Psychosom Res, 65:525-532.

Luthar SS, Cicchetti D, Becker B (2000) Research on resilience: Response to commentaries. Child Dev, 71:573-575.

Lysaker PH, Buck KD, Carcione A, Procacci M, Salvatore G, Nicolò G et al. (2011) Addressing metacognitive capacity for self reflection in the psychotherapy for schizophrenia: a conceptual model of the key tasks and processes. Psychol Psychother, 84:58-69.

Lysaker PH, Carcione A, Dimaggio G, Johannesen J, Nicolò G, Procacci M et al. (2005) Metacognition amidst narratives of self and illness in schizophrenia: associations with neurocognition, symptoms, insight and quality of life. Acta Psychiatr Scand, 112:64-71.

Maguire R, Hanly P, Balfe M, Timmons A, Hyland P, O'Sullivan E et al. (2017) Worry in head and neck Cancer caregivers: the role of survivor factors, care-related stressors, and loneliness in predicting fear of recurrence. Nurs Res, 66:295-303.

Masten AS (2014) Ordinary magic: Resilience in development, New York: Guilford Publications.

Matthews BA (2003) Role and gender differences in cancer-related distress: a comparison of survivor and caregiver self-reports. Oncol Nurs Forum, 30:493-9.

Matzka M, Mayer H, Köck-Hódi S, Moses-Passini C, Dubey C, Jahn P et al. (2016) Relationship between resilience, psychological distress and physical activity in cancer patients: A cross-sectional observation study. PLoS One, 11:e0154496.

McGinty HL, Goldenberg JL, Jacobsen PB (2012) Relationship of threat appraisal with coping appraisal to fear of cancer recurrence in breast cancer survivors. Psychooncology, 21:203-210.

Mellon S, Kershaw TS, Northouse LL, Freeman-Gibb L (2007) A family-based model to predict fear of recurrence for cancer survivors and their caregivers. Psychooncology, 16:214-223.

Mellon S, Northouse LL, Weiss LK (2006) A population-based study of the quality of life of cancer survivors and their family caregivers. Cancer Nurs, 29:120-131.

Min JA, Yoon S, Lee CU, Chae JH, Lee C, Song KY et al. (2013) Psychological resilience contributes to low emotional distress in cancer patients. Support Care Cancer, 21:2469-2476.

Mullens AB, MCCaul KD, Erickson SC, Sandgren AK (2004) Coping after cancer: Risk perceptions, worry, and health behaviors among colorectal cancer survivors. Psychooncology, 13:367-376.

National Cancer Institute (2020) Survivorship. https://www.cancer.gov/publications/dictionaries/cancer-terms/def/survivorship (Accessed 10.11.2020).

Noone A, Howlader N, Krapcho M, Miller D, Brest A, Yu M et al. (2018) SEER cancer statistics review, 1975-2015. National Cancer Institute, https://seer.cancer.gov/archive/csr/1975_2015/ (Accessed 12.10.2020).

Northouse L, Williams Al, Given B, McCorkle R (2012) Psychosocial care for family caregivers of patients with cancer. J Clin Oncol, 30:1227-1234.

Öcalan S, Üzar-0̈zçetin YS (2020) Kanser deneyiminde ruminasyon, tükenmişlik ve psikolojik sağlamlık. Psikiyatride Güncel Yaklaşımlar, 12:421-433.

Öz F, Yilmaz, EB (2009) Ruh sağlğı̆ın korunmasında önemli bir kavram: Psikolojik sağlamlık. Hacettepe Üniversitesi Hemşirelik Fakültesi Dergisi, 16:82-89.

Ries LAG, Harkins D, Krapcho M, Mariotto A, Miller B, Feuer EJ et al. (2006) SEER cancer statistics review, 1975-2003. National Cancer Institute, https://seer.cancer.gov/csr/1975_2003/ (Accessed 12.10.2020). 
Ristevska-Dimitrovska G, Filov I, Rajchanovska D, Stefanovski P, Dejanova B (2015) Resilience and quality of life in breast cancer patients. Open Access Maced J Med Sci, 3:727.

Rosenberg AR, Baker KS, Syrjala KL, Back AL, Wolfe J (2013) Promoting resilience among parents and caregivers of children with cancer. J Palliat Med, 16:645-652.

Rosenberg AR, Wolfe J, Bradford MC, Shaffer ML, Yi-Frazier JP, Curtis JR et al. (2014) Resilience and psychosocial outcomes in parents of children with cancer. Pediatr Blood Cancer, 61:552-557.

Savard J, Ivers $\mathrm{H}$ (2013) The evolution of fear of cancer recurrence during the cancer care trajectory and its relationship with cancer characteristics. J Psychosom Res, 74:354-360.

Schmidt SD, Blank TO, Bellizzi KM, Park CL (2012). The relationship of coping strategies, social support, and attachment style with posttraumatic growth in cancer survivors. J Health Psychol, 17:1033-1040.

Seiler A, Jenewein J (2019) Resilience in cancer patients. Front Psychiatry, 10:208.

Semerari A, Carcione A, Dimaggio G, Falcone M, Nicolò G, Procacci M et al. (2003) How to evaluate metacognitive functioning in psychotherapy? The metacognition assessment scale and its applications. Clin Psychol Psychother, 10:238-261.

Shi Q, Smith TG, Michonski JD, Stein KD, Kaw C, Cleeland CS (2011) Symptom burden in cancer survivors 1 year after diagnosis: A report from the American Cancer Society's Studies of Cancer Survivors. Cancer, 117:2779-2790.

Simard S, Savard J (2015) Screening and comorbidity of clinical levels of fear of cancer recurrence. J Cancer Surviv, 9:481-491.

Simard S, Savard J, Ivers H (2010) Fear of cancer recurrence: Specific profiles and nature of intrusive thoughts. J Cancer Surviv, 4:361371.

Simard S, Thewes B, Humphris G, Dixon M, Hayden C, Mireskandari S et al. (2013) Fear of cancer recurrence in adult cancer survivors: A systematic review of quantitative studies. J Cancer Surviv, 7:300-322.

Smith RA, Andrews KS, Brooks D, Fedewa SA, Manassaram-Baptiste D, Saslow D. et al. (2017) Cancer screening in the United States, 2017: A review of current American Cancer Society guidelines and current issues in cancer screening. CA Cancer J Clin, 67:100-121.

Simonelli LE, Siegel SD, Duffy NM (2017) Fear of cancer recurrence: A theoretical review and its relevance for clinical presentation and management. Psychooncology, 26:1444-1454.

Soriano EC, Pasipanodya EC, LoSavio ST, Otto AK, Perndorfer C, Siegel SD et al. (2018) Social constraints and fear of recurrence in couples coping with early stage breast cancer. Health Psychol, 37:874.

Spada MM, Mohiyeddini C, Wells A (2008) Measuring metacognitions associated with emotional distress: Factor structure and predictive validity of the metacognitions questionnaire 30. Pers Individ Dif, 45:238-242.

Stein KD, Syrjala KL, Andrykowski MA (2008) Physical and psychological long-term and late effects of cancer. Cancer, 112:2577-2592.

Strauss B, Brix C, Fischer S, Leppert K, Füller J, Roehrig B et al. (2007) The influence of resilience on fatigue in cancer patients undergoing radiation therapy (RT). J Cancer Res Clin Oncol, 133:511-518.

Tan JH, Sharpe L, Russell H (2020) The impact of ovarian cancer on individuals and their caregivers: A qualitative analysis. Psychooncology, 1-9.

Thewes B, Bell ML, Butow P (2013) Fear of cancer recurrence in young early-stage breast cancer survivors: The role of metacognitive style and disease-related factors. Psychooncology, 22:2059-2063.

Thewes B, Butow P, Bell ML, Beith J, Stuart-Harris R, Grossi M et al. (2012) Fear of cancer recurrence in young women with a history of early-stage breast cancer: A cross-sectional study of prevalence and association with health behaviours. Supportive Care Cancer, 20:2651-2659.

Tian J, Hong JS (2014) Assessment of the relationship between resilience and quality of life in patients with digestive cancer. World J Gastroenterol, 20:18439.

Tosun A, Irak M (2008) Üstbiliş Ölçeği-30'un Türkçe uyarlaması, geçerliği, güvenirliği, kaygı ve obsesif-kompülsif belirtilerle ilişkisi. Turk Psikiyatri Derg, 19(1).

Üzar-Özçetin YS, Dursun Si (2020) Quality of life, caregiver burden, and resilience among the family caregivers of cancer survivors. Eur J Oncol Nurs, 48:101832.

Üzar-Özçetin YS, Hiçdurmaz D (2017) Kanser Deneyiminde Travma Sonrası Büyüme ve Psikolojik Sağlamlık. Psikiyatride Güncel Yaklaşımlar, 9:388-398.

Üzar-Özçetin YS, Hiçdurmaz D (2019) Effects of an empowerment program on resilience and posttraumatic growth levels of cancer survivors: A randomized controlled feasibility trial. Cancer Nurs, 42:E1-E13. 
van de Wal M, Langenberg S, Gielissen M, Thewes B, van Oort I, Prins J (2017) Fear of cancer recurrence: A significant concern among partners of prostate cancer survivors. Psychooncology, 26:2079-2085.

van den Beuken-van Everdingen MH, Peters ML, de Rijke JM, Schouten HC, van Kleef M, Patijn J (2008) Concerns of former breast cancer patients about disease recurrence: A validation and prevalence study. Psychooncology, 17:1137-1145.

Wagnild GM, Collins JA (2009) Assessing resilience. J Psychosoc Nurs Ment Health Serv, 47:28-33.

Walton M (2017) Lived experience of adult female cancer survivors to discover common protective resilience factors to cope with cancer experience and to identify potential barriers to resilience. J Cancer Ther Res, 13:373-375.

Wells A (2000). Emotional Disorders and Metacognition: Innovative Cognitive Therapy. Chichester, UK: Wiley.

Wells A, Cartwright-Hatton S (2004) A short form of the metacognitions questionnaire: properties of the MCQ-30. Behav Res Ther, 42:385-396.

Wells A, Matthews G (1996) Modelling cognition in emotional disorder: The S-REF model. Behav Res Ther, 34:881-888.

Wells A, Fisher P, Myers S, Wheatley J, Patel T, Brewin CR (2009) Metacognitive therapy in recurrent and persistent depression: A multiple-baseline study of a new treatment. Cognit Ther Res, 33:291-300.

Wu G, Feder A, Cohen H, Kim J, Calderon S, Charney D et al. (2013) Understanding resilience. Front Behav Neurosci, 7:1-15.

Wu LM, McGinty H, Amidi A, Bovbjerg K, Diefenbach MA (2019) Longitudinal dyadic associations of fear of cancer recurrence and the impact of treatment in prostate cancer patients and their spouses. Acta Oncol, 58:708-14.

Zauszniewski JA, Bekhet AK, Suresky MJ (2010) Resilience in family members of persons with serious mental illness. Nurs Clin, 45:613626.

Zuardin AR, Maidin MA, Tamar M, Yani A (2019) Patterns of family support in cervical cancer survivors with high resilience. International Journal of Innovative Technology and Exploring Engineering, 9:1604-1606.

Yazarların Katkıları: Yazarlar çalışmaya önemli bir bilimsel katkı sağladıklarını ve makalenin hazırlanmasında veya gözden geçirilmesinde yardımcı olduklarııı kabul etmişlerdir.

Danışman Değerlendirmesi: Dış bağımsız.

Çıkar Çatışması: Yazarlar çıar çatışması bildirmemiştir.

Finansal Destek: Yazarlar bu çalışma için finansal destek almadığını beyan etmiştir.

Authors Contributions: The authors attest that they have made an important scientific contribution to the study and has assisted with the drafting or revising of the manuscript.

Peer-review: Externally peer-reviewed.

Conflict of Interest: No conflict of interest was declared by the authors.

Financial Disclosure: The authors declared that this study has received no financial support. 